Case Report

\title{
Cerebral Salt Wasting Syndrome following Head Injury in a Child Managed Successfully with Fludrocortisone
}

\author{
Nagendra Chaudhary, Santosh Pathak, Murli Manohar Gupta, and Nikhil Agrawal \\ Department of Pediatrics, Universal College of Medical Sciences, Bhairahawa 32900, Nepal \\ Correspondence should be addressed to Nagendra Chaudhary; enagendra@hotmail.com
}

Received 6 March 2016; Accepted 10 April 2016

Academic Editor: John W. Berkenbosch

Copyright (C) 2016 Nagendra Chaudhary et al. This is an open access article distributed under the Creative Commons Attribution License, which permits unrestricted use, distribution, and reproduction in any medium, provided the original work is properly cited.

Cerebral salt wasting (CSW) syndrome is an important cause of hyponatremia in head injuries apart from syndrome of inappropriate antidiuretic hormone (SIADH). Proper diagnosis and differentiation between these two entities are necessary for management as the treatment is quite opposite in both conditions. Fludrocortisone can help in managing CSW where alone saline infusion does not work. We report a 17-month-old female child with head injury managed successfully with saline infusion and fludrocortisone.

\section{Introduction}

Hyponatremia, a frequently occurring electrolyte disorder in critically ill neurological patients [1], especially traumatic brain injury, if not managed properly can lead to increase in mortality and morbidity [2]. SIADH and CSW are the two common causes of hyponatremia in such patients. The incidence of CSW in brain injury ranges from 0.8 to $34.6 \%$ [3]. SIADH is characterized by inappropriate retention of free water due to increased antidiuretic hormone $(\mathrm{ADH})$ secretion while CSW results in polyuria and natriuresis leading to extracellular volume contraction [4]. It is important to differentiate between both, as SIADH requires fluid restriction while CSW needs saline infusion [5]. A mineralocorticoid, fludrocortisone, has also proven to be beneficial in cases of CSW.

We report a 17-month-old female child with head injury and CSW managed with fludrocortisone which is probably the first case reported from Nepal to the best of our knowledge.

\section{Case Presentation}

A 17-month-old female child was brought to the casualty with alleged history of fall from 2-storey (about 20 feet) building. She had swelling of right side of head with right ear bleeding. On examination, weight was $7.5 \mathrm{~kg}$, pulse rate $110 / \mathrm{min}$, respiratory rate $32 / \mathrm{min}, \mathrm{SPO}_{2} 98 \%$, blood pressure $90 / 60 \mathrm{~mm}$ of $\mathrm{Hg}$, and temperature $98.2^{\circ} \mathrm{F}$. Central nervous system examination revealed Glasgow coma scale (GCS): 10/15 (Eye opening-2, Motor response-4, Verbal-4), sluggishly reacting unequal pupils, increased tone, and extensor plantars. Child was kept nil per oral. She was started on maintenance intravenous fluids (IVF), phenytoin, dexamethasone, and antibiotics (ceftriaxone).

Computed tomography of head was done which suggested fracture of skull bone with subdural hematoma, subarachnoid hemorrhage, extradural hematoma, and contusion (Figures 1(a) and 1(b)). Neurosurgical opinion was sought. Child had multiple episodes of seizures on day 3 of admission which was controlled with phenytoin $(8 \mathrm{mg} / \mathrm{kg} /$ day $)$, valproate $(50 \mathrm{mg} / \mathrm{kg} /$ day $)$, and levetiracetam $(40 \mathrm{mg} / \mathrm{kg} /$ day).

Child was then planned for oral feeding. Child gradually tolerated feeds well and intravenous fluid was stopped. The next day (day 10), child had polyuria $(9 \mathrm{~mL} / \mathrm{kg} / \mathrm{hr})$ with hyponatremia $(128 \mathrm{meq} / \mathrm{L})$. Blood urea was $22 \mathrm{mg} / \mathrm{dL}$ and serum creatinine was $0.6 \mathrm{mg} / \mathrm{dL}$. Possibility of SIADH and CSW was considered. Urine osmolality and urine sodium were $400 \mathrm{mosmol} / \mathrm{L}$ and $146 \mathrm{meq} / \mathrm{L}$, respectively, whereas serum osmolality was $265 \mathrm{mosmol} / \mathrm{L}$. Serum uric acid was $3.5 \mathrm{mg} / \mathrm{dL}$. Fractional excretion of sodium (4.16\%) and uric acid (24.8\%) was raised. Serum ADH level was within normal 


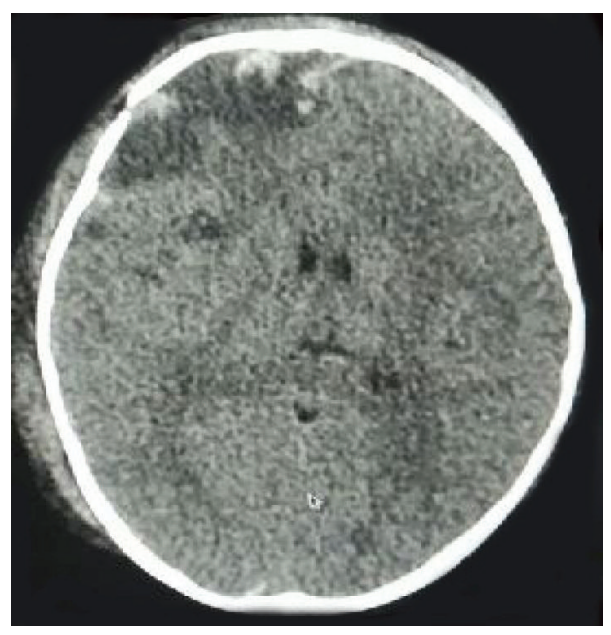

(a)

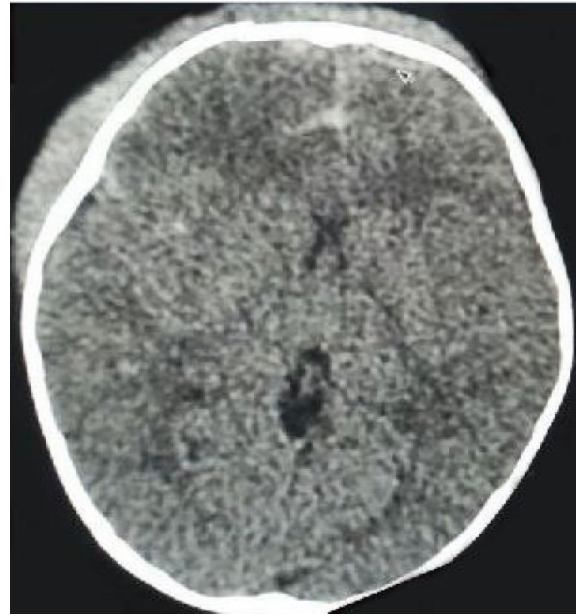

(b)

Figure 1: Computed tomography of head showing fracture of right frontal bone and subdural hematoma and extradural hematoma with contusion and subarachnoid hemorrhage.

limits. She was diagnosed to have CSW as she had increased urinary $\mathrm{Na}^{+}$excretion with polyuria and hyponatremia. Urinary replacement (volume to volume) with normal saline was done every 1-2 hours depending on the polyuria. Saline (DNS) infusion was given as maintenance fluid. As she still had hyponatremia, $3 \% \mathrm{NaCl}$ infusion at $0.1 \mathrm{~mL} / \mathrm{kg} / \mathrm{hr}$ too was considered (maximum rate up to $0.3 \mathrm{~mL} / \mathrm{kg} / \mathrm{hr}$ ) through central line (femoral line). Maximum amount of sodium infused was $41 \mathrm{meq} / \mathrm{kg} /$ day. Child's polyuria (reached up to $15 \mathrm{~mL} / \mathrm{kg} / \mathrm{hr}$ ) was not controlled despite saline infusion. Child was then (day 13) started on oral fludrocortisone $0.1 \mathrm{mg} /$ day, in two divided doses which increased to $0.2 \mathrm{mg} /$ day after 2 days. Serum electrolytes and blood pressure monitoring were done regularly. Urine output improved gradually and polyuria subsided (Figure 2). Fludrocortisone was gradually tapered and stopped on day 20 of admission. Child also received two packed red blood cell transfusions during the admission period. Figure 2 shows the relationship of urine output, serum sodium, and urinary sodium concentration before and after treatment with fludrocortisone.

She was then started on oral feeding and intravenous fluid was gradually tapered. On discharge, child's sensorium was normal and she was on full feeds and had normal urine output and no seizures.

\section{Discussion}

CSW is characterized by hyponatremia and increased loss of sodium in urine with volume depletion and generally occurring in patients with head injuries [6], infections [7], or tumours. Hyponatremia is also common (30\%) in patients with SAH. Peters et al. reported CSW as a salt wasting syndrome associated with cerebral disease in 1950s [8]. Some authors have reported that CSW is as common as SIADH [9]. The prevalence data in children is scarce with few case reports and case series $[10,11]$. The postulated pathophysiology of CSW in head injury is (a) increased sympathetic activity

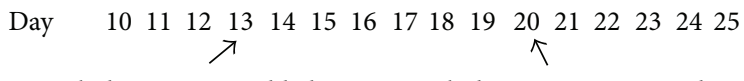

Fludrocortisone added Fludrocortisone stopped
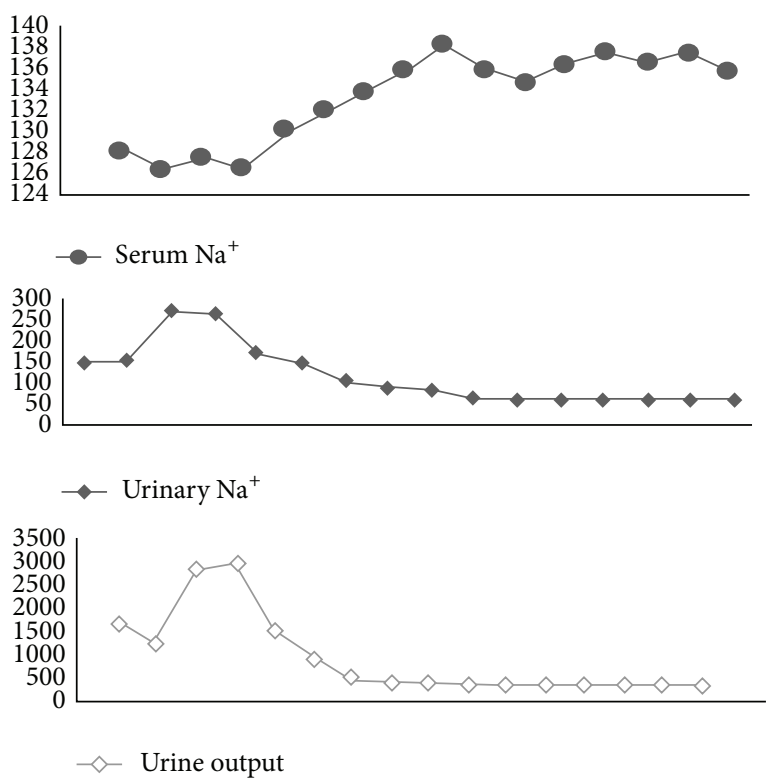

Figure 2: Relationship of urine output (mL/day), serum sodium (meq/L), and urinary sodium (meq/L) before and after treatment with fludrocortisone.

and dopamine release causing natriuresis; (b) increased brain natriuretic peptide (BNP) by the injured brain; and (c) failure of renin aldosterone system [11, 12]. The treatments of hyponatremia in SIADH and CSW are completely opposite although both require increased salt intake. Improper diagnosis of the cause of hyponatremia may lead to inappropriate fluid restriction in CSW or fluid and salt supplementation in SIADH [13]. 
TABLE 1: Differences between CSW and SIADH $[16,17]$.

\begin{tabular}{lcc}
\hline Features & CSW & SIADH \\
\hline Dehydration & Present & Absent \\
Serum sodium & Decreased & Decreased \\
Urinary sodium excretion & Increased & Variable \\
Urine osmolality & Increased & Increased \\
Serum osmolality & Low & Low \\
Vasopressin & Low & High \\
Polyuria & Present & Absent \\
BUN & Increased & Normal \\
Blood pressure & Low & Normal or increased \\
ANP & Increased & Normal \\
Treatment & Saline $/ 3 \% \mathrm{NaCl}$ & Fluid restriction \\
\hline
\end{tabular}

CSW is characterized by increased urinary sodium loss (increased $\mathrm{FENa}^{+}$), resulting in hyponatremia and finally extracellular fluid volume contraction whereas SIADH involves increased renal sensitivity to $\mathrm{ADH}$ or inappropriate $\mathrm{ADH}$ secretion which in turn leads to water conservation (dilutional hyponatremia) [2, 14]. Natriuretic peptides (ANP, BNP) are generally raised in CSW [15]. There is increased fractional excretion of uric acid in both CSW and SIADH, where the excretion improves in SIADH after correction but persists in CSW. BUN is generally raised in CSW and low in SIADH; however this is not universal in all cases. Inability to differentiate between them can lead to serious consequences. The salient differentiating points are given in Table 1.

Children with CSW generally have low blood pressure and even shock due to polyuria, increased urinary sodium loss, and contraction of extracellular fluid. Volume status determination remains difficult in such cases which requires CVP measurement [18]. Our patient also had low blood pressure which was managed with fluid boluses, maintenance intravenous fluid (5\% DNS), and vasopressors (dopamine).

Fluid restriction is required in SIADH whereas saline infusion $(0.9 \% \mathrm{NS} / 3 \%$ saline) is needed in treatment of CSW [11]. Although CSW should be treated aggressively, one should be cautious not to raise serum sodium $>0.5 \mathrm{meq} / \mathrm{L} / \mathrm{hr}$ to prevent pontine myelinolysis. Cases not responding alone to saline infusion should be treated with fludrocortisone, a synthetic mineralocorticoid.

The use of fludrocortisone in CSW has been reported in 1980 s in adult patients with head injury $[19,20]$. Data of its use in pediatric population with CSW has been reported sporadically [21-23]. Ozdemir et al. reported successful use of fludrocortisone in a 34-month-old child with lissencephaly who developed CSW after brain biopsy [17]. The duration of its use is variable. In a series of 4 cases reported by Taplin et al., fludrocortisone has been used for 4-125 days, with doses ranging from 0.2 to $0.4 \mathrm{mg} /$ day [11]. Prolonged and high doses can lead to high blood pressure and sodium and water retention and hypokalemia [11].

\section{Conclusion}

CSW should always be considered whenever a clinician encounters hyponatremia in patients with cerebral disorders. One can diagnose CSW in hyponatremic patients by establishing contraction of extracellular volume. Increased urinary sodium and urate excretion and high urine osmolality and polyuria with elevated natriuretic peptides support the diagnosis. Fludrocortisone can be an effective drug in the management of CSW apart from saline infusion.

\section{Consent}

Verbal and written consent were obtained from the parents for publication.

\section{Competing Interests}

The authors declare that there is no conflict of interests regarding the publication of this paper.

\section{Authors' Contributions}

All authors are equally involved in drafting, literature search, and writing of the paper.

\section{Acknowledgments}

The authors acknowledge the parents of the patient for giving permission to publish the case.

\section{References}

[1] S.-J. Lee, E.-J. Huh, and J.-H. Byeon, “Two cases of cerebral salt wasting syndrome developing after cranial vault remodeling in craniosynostosis children," Journal of Korean Medical Science, vol. 19, no. 4, pp. 627-630, 2004.

[2] M. R. Harrigan, "Cerebral salt wasting syndrome: a review," Neurosurgery, vol. 38, no. 1, pp. 152-160, 1996.

[3] J. Leonard, R. E. Garrett, K. Salottolo et al., "Cerebral salt wasting after traumatic brain injury: a review of the literature," Scandinavian Journal of Trauma, Resuscitation and Emergency Medicine, vol. 23, article 98, 2015.

[4] M. R. Harrigan, "Cerebral salt wasting syndrome," Critical Care Clinics, vol. 17, no. 1, pp. 125-138, 2001.

[5] C. A. Ganong and M. S. Kappy, "Cerebral salt wasting in children. The need for recognition and treatment," American Journal of Diseases of Children, vol. 147, no. 2, pp. 167-169, 1993.

[6] P. C. M. Donati-Genet, J.-M. Dubuis, E. Girardin, and P. C. Rimensberger, "Acute symptomatic hyponatremia and cerebral salt wasting after head injury: an important clinical entity," Journal of Pediatric Surgery, vol. 36, no. 7, pp. 1094-1097, 2001.

[7] A. Jabbar, S. N. Farrukh, and R. Khan, "Cerebral salt wasting syndrome in tuberculous meningitis," Journal of the Pakistan Medical Association, vol. 60, no. 11, pp. 964-965, 2010.

[8] J. P. Peters, L. G. Welt, E. A. Sims, J. Orloff, and J. Needham, "A salt-wasting syndrome associated with cerebral disease," Transactions of the Association of American Physicians, vol. 63, pp. 57-64, 1950. 
[9] P. B. Nelson, S. M. Seif, J. C. Maroon, and A. G. Robinson, "Hyponatremia in intracranial disease: perhaps not the syndrome of inappropriate secretion of antidiuretic hormone (SIADH)," Journal of Neurosurgery, vol. 55, no. 6, pp. 938-941, 1981.

[10] J. W. Berkenbosch, C. W. Lentz, D. F. Jimenez, and J. D. Tobias, "Cerebral salt wasting syndrome following brain injury in three pediatric patients: suggestions for rapid diagnosis and therapy," Pediatric Neurosurgery, vol. 36, no. 2, pp. 75-79, 2002.

[11] C. E. Taplin, C. T. Cowell, M. Silink, and G. R. Ambler, "Fludrocortisone therapy in cerebral salt wasting," Pediatrics, vol. 118, no. 6, pp. e1904-e1908, 2006.

[12] E. Berendes, M. Walter, P. Cullen et al., "Secretion of brain natriuretic peptide in patients with aneurysmal subarachnoid haemorrhage," The Lancet, vol. 349, no. 9047, pp. 245-249, 1997.

[13] E. F. M. Wijdicks, M. Vermeulen, J. A. Ten Haaf, A. Hijdra, W. H. Bakker, and J. van Gijn, "Volume depletion and natriuresis in patients with a ruptured intracranial aneurysm," Annals of Neurology, vol. 18, no. 2, pp. 211-216, 1985.

[14] A. H. Yee, J. D. Burns, and E. F. M. Wijdicks, "Cerebral salt wasting: pathophysiology, diagnosis, and treatment," Neurosurgery Clinics of North America, vol. 21, no. 2, pp. 339-352, 2010.

[15] P. von Bismarck, T. Ankermann, P. Eggert, A. Claviez, M. J. Fritsch, and M. F. Krause, "Diagnosis and management of cerebral salt wasting (CSW) in children: the role of atrial natriuretic peptide (ANP) and brain natriuretic peptide (BNP)," Child's Nervous System, vol. 22, no. 10, pp. 1275-1281, 2006.

[16] M. Cerdà-Esteve, E. Cuadrado-Godia, J. J. Chillaron et al., "Cerebral salt wasting syndrome: review," European Journal of Internal Medicine, vol. 19, no. 4, pp. 249-254, 2008.

[17] H. Ozdemir, Z. Aycan, A. Degerliyurt, and A. Metin, "The treatment of cerebral salt wasting with fludrocortisone in a child with lissencephaly," Turkish Neurosurgery, vol. 20, no. 1, pp. 100$102,2010$.

[18] H.-M. Chung, R. Kluge, R. W. Schrier, and R. J. Anderson, "Clinical assessment of extracellular fluid volume in hyponatremia," The American Journal of Medicine, vol. 83, no. 5, pp. 905-908, 1987.

[19] S.-E. Ishikawa, T. Saito, K. Kaneko, K. Okada, and T. Kuzuya, "Hyponatremia responsive to fludrocortisone acetate in elderly patients after head injury," Annals of Internal Medicine, vol. 106, no. 2, pp. 187-191, 1987.

[20] M. S. Kappy and C. A. Ganong, "Cerebral salt wasting in children: the role of atrial natriuretic hormone," Advances in Pediatrics, vol. 43, pp. 271-308, 1996.

[21] S. T. Kinik, N. Kandemir, A. Baykan, N. Akalan, and N. Yordam, "Fludrocortisone treatment in a child with severe cerebral salt wasting," Pediatric Neurosurgery, vol. 35, no. 4, pp. 216-219, 2001.

[22] A. Sakarcan and J. Bocchini Jr., "The role of fludrocortisone in a child with cerebral salt wasting," Pediatric Nephrology, vol. 12, no. 9, pp. 769-771, 1998.

[23] L. Nagotkar, P. Shanbag, and N. Dasarwar, "Cerebral salt wasting syndrome following neurosurgical intervention in tuberculous meningitis," Indian Pediatrics, vol. 45, no. 7, pp. 598-601, 2008. 


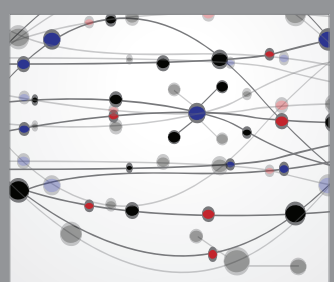

The Scientific World Journal
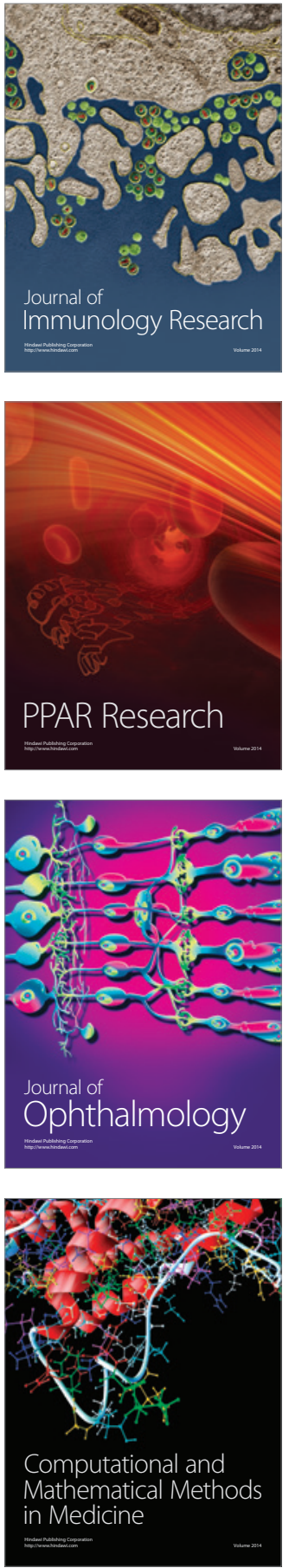

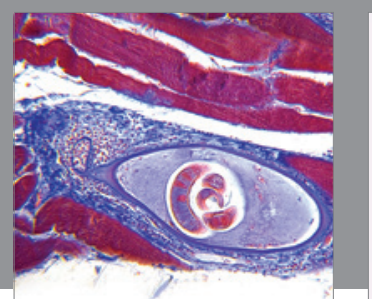

Gastroenterology Research and Practice

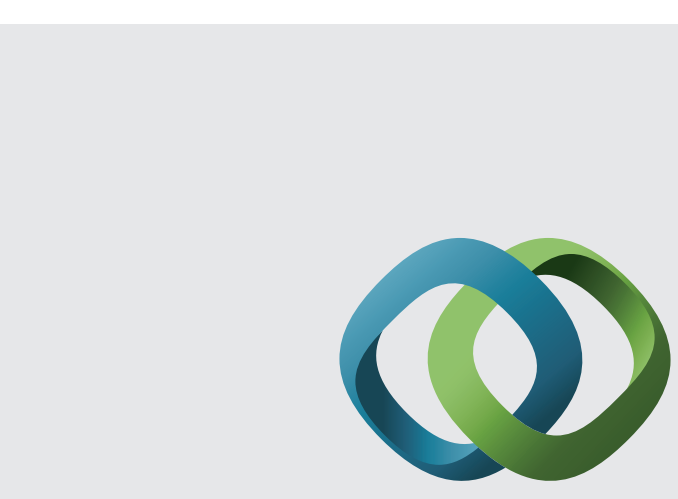

\section{Hindawi}

Submit your manuscripts at

http://www.hindawi.com
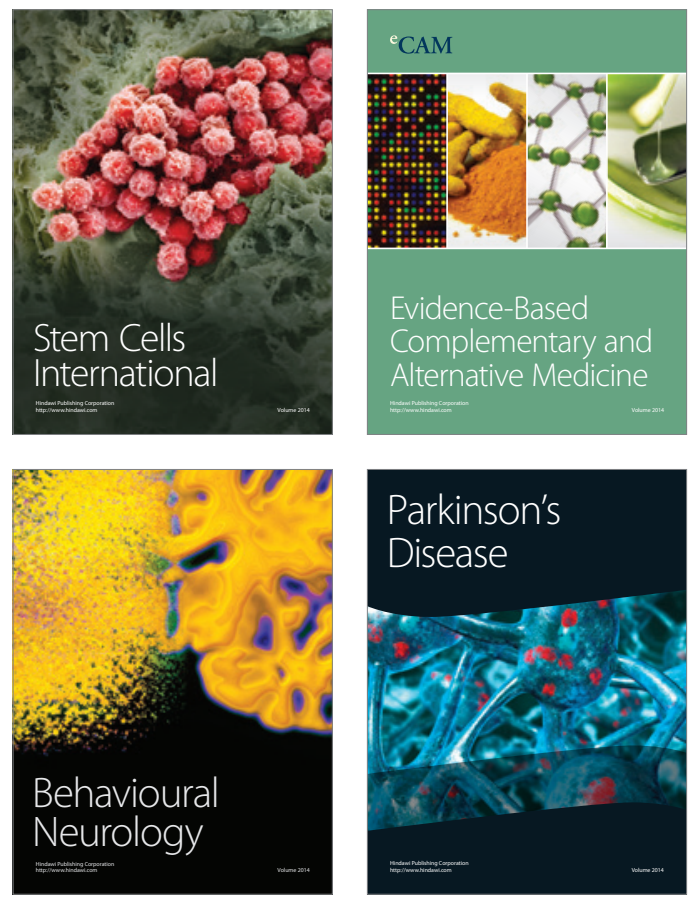
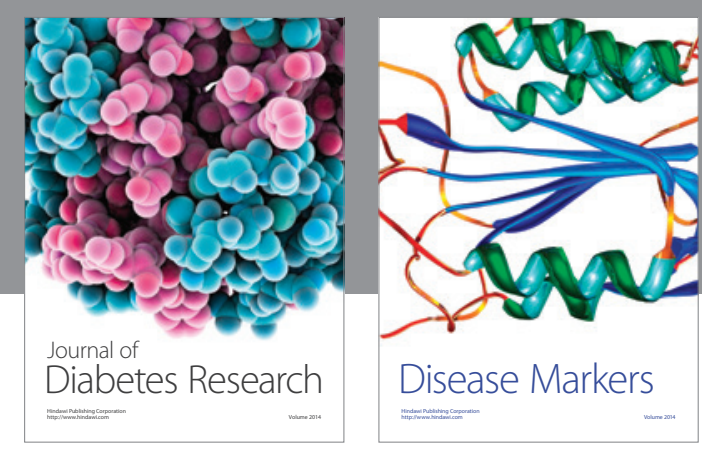

Disease Markers
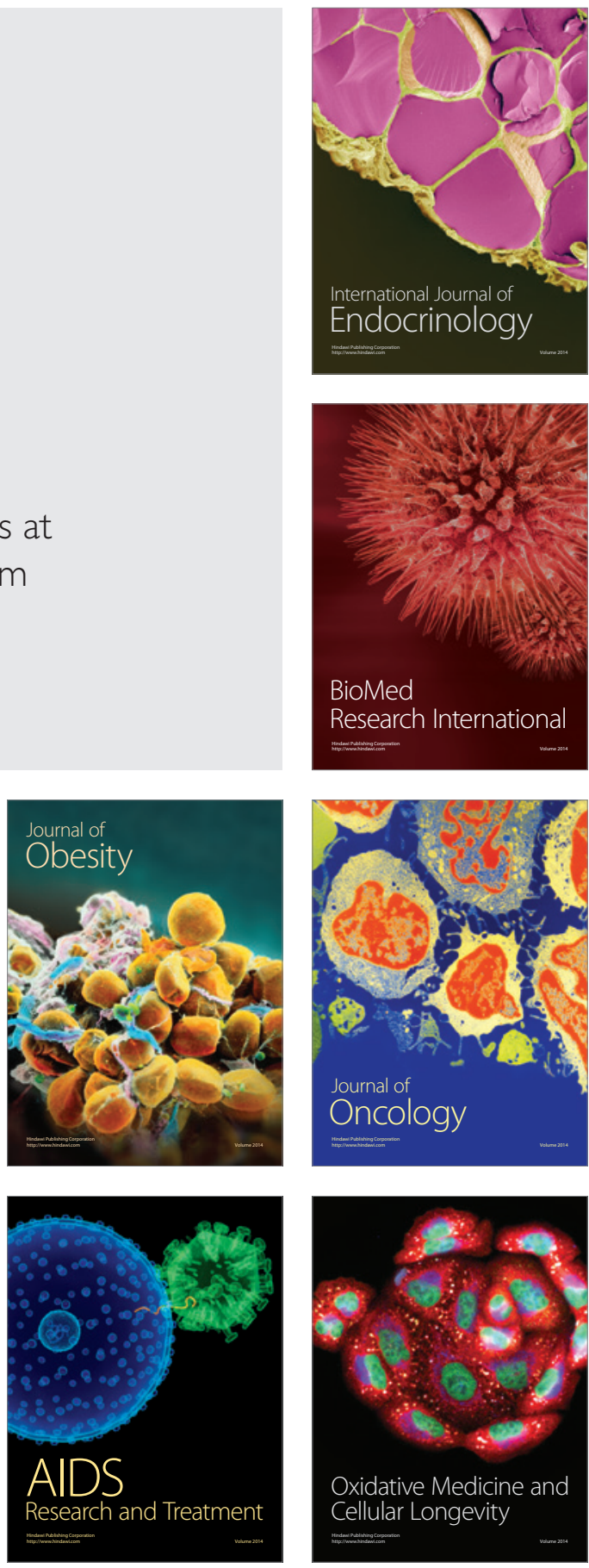